\title{
Regional cerebral blood flow in IDDM patients: effects of diabetes and of recurrent severe hypoglycaemia
}

\author{
K.M.MacLeod ${ }^{1}$, D.A.Hepburn ${ }^{1}$, I.J.Deary ${ }^{2}$, G.M. Goodwin ${ }^{3}$, N.Dougall ${ }^{3}$, K.P.Ebmeier ${ }^{3}$, B.M. Erier $^{1}$ \\ ${ }^{1}$ Department of Diabetes, Royal Infirmary, Edinburgh, Scotland \\ ${ }^{2}$ Department of Psychology, University of Edinburgh, Edinburgh, Scotland \\ ${ }^{3}$ MRC Brain Metabolism Unit, Royal Edinburgh Hospital, Edinburgh, Scotland
}

Summary Chronic hyperglycaemia and recurrent severe hypoglycaemia have both been implicated as causing cerebral damage in patients with diabetes. Although cognitive dysfunction and intellectual impairment have been demonstrated in patients with recurrent severe hypoglycaemia, structural correlates have not been described, and it is not known whether specific functional changes occur in the brains of affected patients. Regional cerebral blood flow was estimated by SPECT with ${ }^{99 \mathrm{~m}}$ Technetium Exametazime in 20 patients with IDDM. Ten patients had never experienced severe hypoglycaemia and 10 had a history of recurrent severe hypoglycaemia. Patient results were compared with 20 age- and sex-matched healthy volunteers. We obser- ved differences between the two patient groups and the control group. Tracer uptake was greater in diabetic patients in the superior pre-frontal cortex. This effect was particularly pronounced in the group who had a history of previous severe hypoglycaemia. Patients with a history of recurrent hypoglycaemia also had a relative reduction in tracer uptake to the calcarine cortex. This suggests an alteration in the pattern of baseline regional cerebral blood flow in diabetic patients with frontal excess and relative posterior reduction in cerebral blood flow. [Diabetologia (1994) 37: 257-263]

Key words Diabetes mellitus, hypoglycaemia, cerebral blood flow, SPECT.
Diabetes mellitus, with its associated disturbances in glucose metabolism has been shown to be associated with functional cerebral impairment [1-5]. Because glucose is the obligate fuel of the brain, acute hypoglycaemia causes profound but reversible changes in neurophysiological performance with, for example, reproducible EEG changes. Although controversy surrounds precisely which areas of the brain are most vulnerable to neuroglycopenia, with respect to EEG changes, the frontal, parieto-occipital and temporal

Received: 19 May 1993

and in revised form: 6 September 1993

Corresponding author: Dr. K. M. MacLeod, Department of Diabetes, Royal Infirmary, Lauriston Place, Edinburgh EH3 9YW, Scotland

Abbreviations: IDDM, insulin-dependent diabetes mellitus; SPECT, single photon emission computed tomography; EEG, electroencephalograph; ANOVA, analysis of variance. areas have been observed to be particularly sensitive [6-9].

An important issue is whether recurrent severe hypoglycaemia causes permanent alteration of brain function. Retrospective studies have reported permanent reductions of cognitive functioning in diabetic patients who had suffered multiple episodes of severe hypoglycaemia, none of which had been recognised to cause lasting intellectual or neurological deficits at the time [10-12]. Our group has previously shown [12] that the frequency of recurrent severe hypoglycaemia correlated significantly with a measure of cognitive decline from premorbid IQ levels in 100 insulin-treated diabetic patients. In a subsequent report [13], we found that repeated severe hypoglycaemia appeared to affect particularly those information processing stages associated with decision-making and response initiation. Those patients with a history of multiple exposures to severe hypoglycaemia had lower performance IQs and verbal IQs than 100 closely matched non-diabetic control subjects, and the history of recurrent severe hypo- 
glycaemia appeared to account for the performance IQ deficit but not the shortfall in verbal IQ [13]. Reduced verbal IQ could be attributed to diabetes per se but not to severe hypoglycaemia. The aim of the present study was to investigate whether disturbance of brain metabolic functioning might co-exist with these detectable cognitive changes in a subgroup of the diabetic patients who had been studied previously.

\section{Subjects, materials and methods}

\section{Subjects}

Twenty subjects with IDDM were recruited from a cohort of 100 patients who had been studied previously to examine the relationship between a history of repeated exposure to severe hypoglycaemia and cognitive functioning [12]. Patients with a history of cerebrovascular disease, head injury, serious systemic disease, alcohol abuse or major psychiatric illness were excluded. All the patients had developed diabetes after the age of 19 years and had a duration of illness of more than 6 years. Ten of the patients for the present study were recruited from a subgroup who had experienced five or more episodes of severe hypoglycaemia since commencing treatment with insulin, and 10 patients from a subgroup with no previous history of severe hypoglycaemia, who had no evidence of cognitive impairment. All subjects were studied according to a protocol approved by the Administration of Radioactive Substances Advisory Committee (ARSAC) in the United Kingdom and the local Medical Ethical Advisory Committee. Written informed consent was obtained from all subjects.

\section{Assessment of cognitive ability and anxiety}

The National Adult Reading Test (NART), [14] was used to assess the pre-morbid IQ i.e. the peak cognitive ability attained by a patient prior to any intellectual decline. This measure is resistant to organic brain damage. The Wechsler Adult Intelligence Scale - Revised (WAIS-R, [15]) was used to assess current intellectual functioning. Verbal, performance and full scale IQs were obtained. The WAIS-R IQ correlates highly with the NART in healthy adults. To assess levels of state anxiety, the Spielberger State Anxiety Questionnaire [16] was administered.

\section{Preparation for the study}

The study was not performed if the patient had experienced symptomatic, or recorded biochemical, hypoglycaemia in the preceding $24 \mathrm{~h}$. The studies were performed in the afternoon. To reduce the risk of hypoglycaemia, the patients were asked to reduce the dose of isophane insulin the previous evening by $2 \mathrm{IU}$. On the morning of the study, they omitted the isophane insulin and reduced the soluble insulin by $2 \mathrm{IU}$.

\section{Maintenance of normoglycaemia}

At regular (5-min) intervals throughout the study venous blood was drawn for determination of blood glucose by automated colorimetric analysis (BM stix and Reflolux IIM; Boehringer, Lewes,
UK). The blood glucose concentration was maintained in the target range of 5 to $10 \mathrm{mmol} / 1$ by a continuous infusion of $5 \%$ dextrose and soluble (unmodified) insulin (Actrapid; Novo Nordisk, Basingstoke, UK) at a variable rate through an indwelling antecubital venous catheter. The absolute fall, and rate of fall of blood glucose to near normoglycaemia was similar in both groups.

\section{Imaging procedure}

All subjects were examined with a single slice multi-detector dedicated head scanner (Multi-X 810; Strichman Medical Equipment Inc., Boston, Mass., USA) after an i.v. bolus injection of ${ }^{99 \mathrm{~m}} \mathrm{Tc}-\mathrm{Exametazime}$. The single photon (gamma) emitter ${ }^{99}$ Technetium-Exametazime (hexamethyl propylene amine oxime) is taken up avidly into brain cells on first pass after i. v. injection. About $85 \%$ of the tracer is retained in situ, so that the activity which is measurable for hours after the injection reflects the distribution of regional cerebral blood flow [17-20]. Under physiological conditions, both at rest and during activation, regional cerebral blood flow closely mirrors cerebral metabolic activity $[21,22]$. Although SPECT is generally described as a "functional imaging method", measured tracer activity is also reduced if there is a "structural" reduction of tissue mass.

Using the intermediate 572 hole collimators, the maximum in-slice resolution of the scanner is given as $7.5 \mathrm{~mm}$ (full width, half maximum) by $15-\mathrm{mm}$ slice thickness. The sensitivity of the instrument has been measured as 520 counts per second per $1 \mathrm{kBq} / \mathrm{ml}$ [23]. The patients were scanned at rest and again during the performance of the PASAT task, using a split-dose technique [23]. PASAT is a paced auditory serial addition test [24]. The resting and activation scans will be compared to explore the effects of PASAT activation and these effects described in a subsequent report, but the present study describes the baseline results. At baseline, the subjects were lying comfortably on theimaging table with their eyes covered and their ears unplugged. Ambient noise was kept to a minimum for $5 \mathrm{~min}$ after commencing the tracer injection. A dose of $250 \mathrm{MBq}$ of the tracer was injected as an i.v. bolus through an antecubital Teflon catheter. The subject's head was then placed in a moulded head rest, and positioned parallel to the orbito-meatal line with the help of two crossed positioning lights, and fixed with pressure pads over the zygomatic arches. Two slices parallel to the orbito-meatal line were acquired at levels of +4 and $+6 \mathrm{~cm}$. The scan acquisition time was $5-\mathrm{min} / \mathrm{slice}$ with total slice counts of approximately $1,000,000$.

\section{Imaging analysis}

Local count densities were examined using a region of interest approach. Templates were derived from a standard neuroanatomical atlas [25] and fitted by aligning the outer border of the template with the $40 \%$ isocontour line of the brain activity map (Fig. 1). This method avoids the arbitrary definition of regions of interest centred on local hot spots, which would introduce a bias. The reliability of this method has been demonstrated previously [23]. Raw count densities were normalised by dividing regional values by the area weighted mean of all regions of interest in the two slices examined.

\section{Statistical analysis}

Normalised count densities were compared between the nondiabetic and the two diabetic groups using one way ANOVA. Since these comparisons were exploratory in nature, protection 

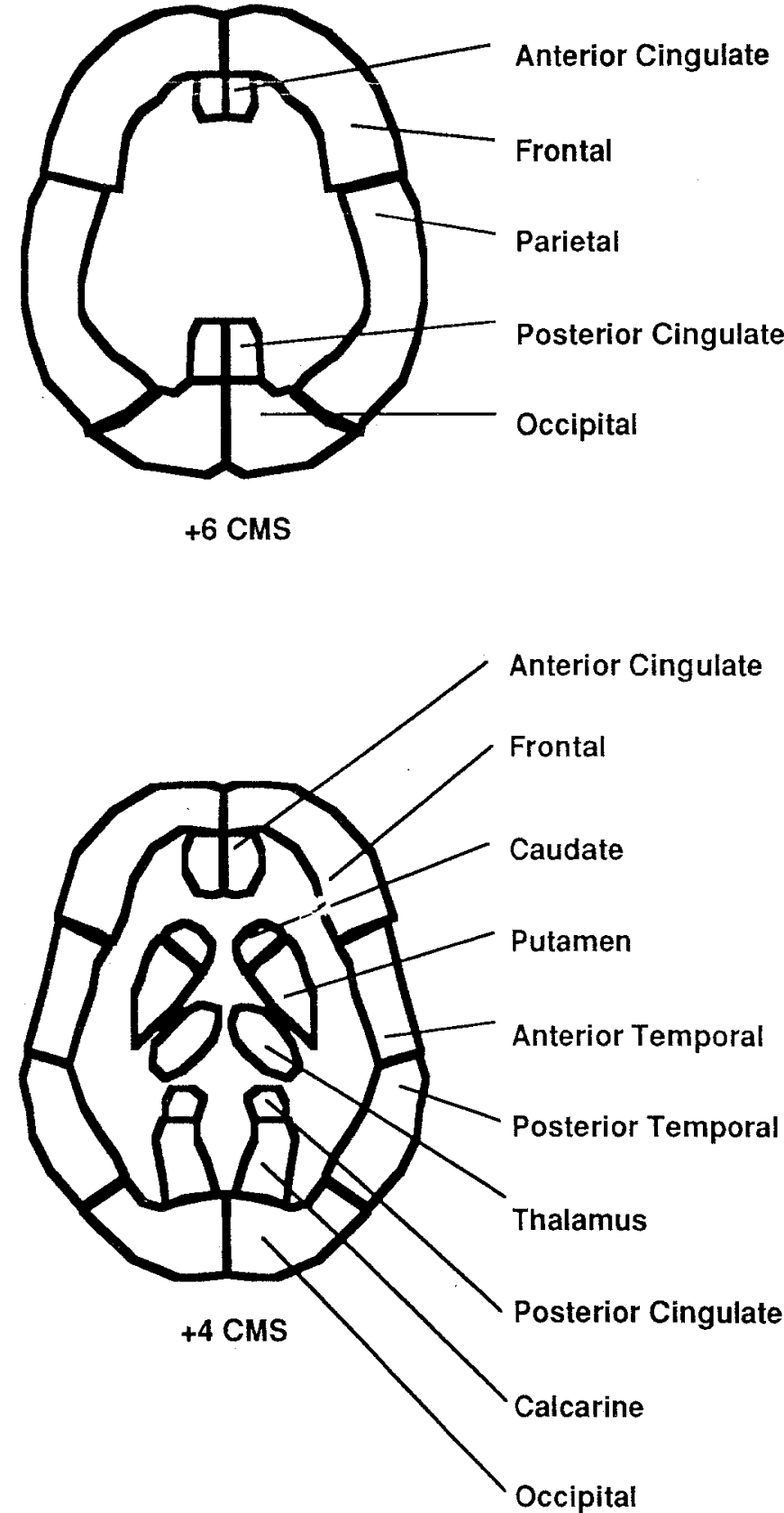

Fig. 1. Regions of interest in the two templates used for transaxial (horizontal) slices at the level of the basal ganglia $(4 \mathrm{~cm}$ above the orbito-meatal line) and a second slice parallel to the first and $2 \mathrm{~cm}$ higher. (Figure modified from [31] with permission)

against type 1 errors by the application of multivariate tests or Bonnferroni correction was not carried out. Where there was an overall group effect in the one way ANOVA, group values were compared using post hoc Scheffe tests. The hypothesis that the duration of illness (i.e. the likely effects of chronic hyperglycaemia) affects regional tracer uptake was tested by non-parametric correlations.

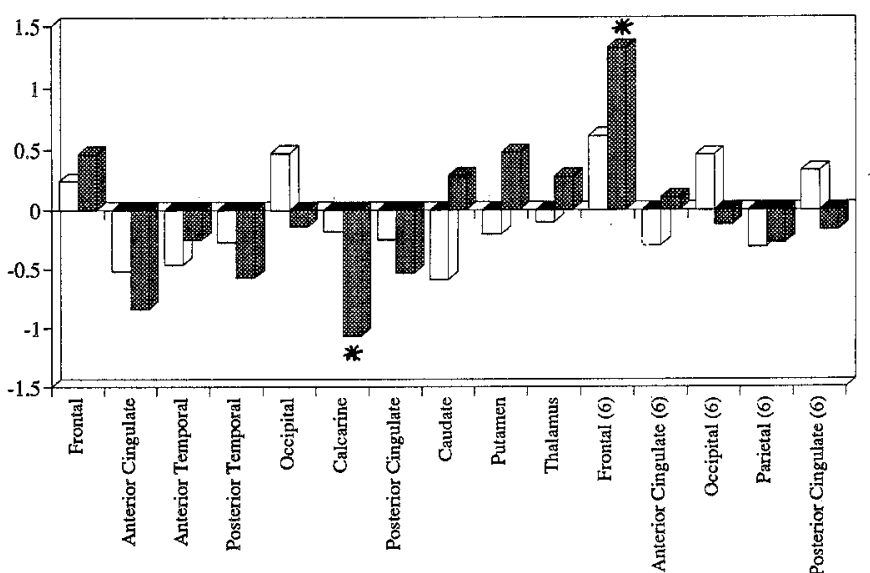

Fig. 2. Profile of group differences between the two patient groups, those without hypoglycaemia $\square$ and those with hypoglycaemia $\mathbf{E}$, and aged matched control subjects. Normalised tracer uptake values have been transformed and expressed as deviation from control mean in control SD units (effect sizes). A value of +1 , indicates a patient value $1 \mathrm{SD}$ above the control mean. Significant differences $(p<0.05)$ have been indicated by an asterisk $(*)$. (6) refers to the cortical area at higher trans-axial slice i. e. at plus $6 \mathrm{~cm}$ above the orbito-meatal line

\section{Results}

The two patient groups and the control group were matched for age, sex, social class and years of education (Table 1). In Table 2, the results are shown of the psychometric assessment including the estimated level of anxiety at the time of the scan, the duration of diabetes and the quality of glycaemic control of the two groups of patients with diabetes. The quality of glycaemic control was stable within groups and was similar between groups. The groups did not differ significantly in premorbid IQ as estimated by the corrected NART [12, $14]$ or in verbal, performance and full scale IQ, as estimated by the WAIS-R [15]. Those patients in the original study [12] who had experienced five or more episodes of severe hypoglycaemia had a significantly greater deterioration in IQ performance, as estimated by the difference between NART and WAIS-R IQ, than those with no history of hypoglycaemia. Because of the smaller number, the patients with frequent severe hypoglycaemia recruited for this study, however, did not show such a significant IQ difference (Table 2). The Spielberger State Anxiety Questionnaire [16] was administered $5 \mathrm{~min}$ after the injection of radioisotope; no between-group differences in the state of anxiety were demonstrated.

The ANOVA did not produce any overall left-right effects $\left(F_{2,37}=1.21 ; p=0.31\right)$, nor were there any regional left-right differences (Hotellings $\mathrm{T}=1.08$; $F_{28,46}=0.89 ; p=0.62$ ). Consequently, left and right regional uptake ratios were averaged (Table 3 ). No differences were observed between the two patient groups, but differences were apparent between diabetic patients and the control subjects. Increased tracer uptake 
Table 1. Socio-demographic characteristics of diabetic patients with and without recurrent exposure to previous severe hypoglycaemia and normal control subjects

\begin{tabular}{llll}
\hline & $\begin{array}{l}\text { Without hypoglycaemia } \\
(n=10)\end{array}$ & $\begin{array}{l}\text { With hypoglycaemia } \\
(n=10)\end{array}$ & $\begin{array}{l}\text { Non-diabetic control } \\
\text { subjects }(n=20)\end{array}$ \\
\hline Age (years) & $39.1 \pm 5.7$ & $38.6 \pm 6.0$ & $38.8 \pm 11.2$ \\
Sex (male/female) & $7 / 3$ & $7 / 3$ & $8 / 12$ \\
Social class (grouping) & $1 / 5 / 4 / 0 / 0$ & $0 / 3 / 6 / 0 / 1$ & $3 / 6 / 10 / 0 / 1$ \\
Education (years) & $12.5 \pm 2.5$ & $12.8 \pm 3.1$ & $14.1 \pm 3.25$ \\
\hline
\end{tabular}

Table 2. Psychometric assessment, state anxiety, duration of diabetes and quality of glycaemic control in diabetic patients with and without a history of severe hypoglycaemia

\begin{tabular}{lcc}
\hline & Without hypoglycaemia $(n=10)$ & With hypoglycaemia $(n=10)$ \\
\hline NART IQ & $107.7 \pm 4.7$ & $103.5 \pm 10.7$ \\
WAIS-R IQ & $107.4 \pm 13.0$ & $98.0 \pm 18.9$ \\
WAIS - Performance & $106.9 \pm 12.3$ & $96.1 \pm 19.2$ \\
WAIS - Verbal & $107.1 \pm 12.7$ & $99.8 \pm 17.3$ \\
Spielberger & $26.8 \pm 3.5$ & $29.1 \pm 6.5$ \\
$\mathrm{HbA}_{1}$, last 6 months (\%) & $9.5 \pm 1.7$ & $10.1 \pm 1.9$ \\
$\mathrm{HbA}$, previous 6 months (\%) & $9.9 \pm 1.6$ & $10.4 \pm 2.0$ \\
$\mathrm{BMI}\left(\mathrm{kg} \cdot \mathrm{m}^{-2}\right.$ ) & $24.8 \pm 2.3$ & $26.4 \pm 2.5$ \\
Insulin dose (units $\left.\cdot \mathrm{kg}^{-2}\right)$ & $0.62 \pm 0.3$ & $0.61 \pm 0.3$ \\
Duration diabetes (year) & $10.5 \pm 3.8$ & $11.9 \pm 3.9$ \\
\hline
\end{tabular}

Table 3. Count densities of the regions of interest, normalised to the mean count density in all regions of interest

\begin{tabular}{|c|c|c|c|c|c|}
\hline & $\begin{array}{l}\text { 1. Without hypogly- } \\
\text { caemia } \\
\text { Mean } \pm \text { S.D }\end{array}$ & $\begin{array}{l}\text { 2. With hypogly- } \\
\text { caemia } \\
\text { Mean } \pm \text { S.D }\end{array}$ & $\begin{array}{l}\text { 3. Control sub- } \\
\text { jects } \\
\text { Mean } \pm \text { S.D }\end{array}$ & $\begin{array}{l}\text { ANOVA } \\
F_{2,37}(p)\end{array}$ & $\begin{array}{l}\text { Post-hoc test } \\
\text { (Scheffe) }\end{array}$ \\
\hline Frontal & $0.96 \pm 0.04$ & $0.97 \pm 0.04$ & $0.95 \pm 0.03$ & & \\
\hline Frontal - (upper slice) & $0.95 \pm 0.03$ & $0.98 \pm 0.03$ & $0.94 \pm 0.03$ & $3.8(0.03)$ & $3<2$ \\
\hline Anterior cingulate & $1.08 \pm 0.08$ & $1.05 \pm 0.06$ & $1.10 \pm 0.05$ & & \\
\hline Anterior cingulate - (upper slice) & $1.10 \pm 0.06$ & $1.12 \pm 0.06$ & $1.12 \pm 0.05$ & & \\
\hline Caudate & $0.90 \pm 0.10$ & $0.96 \pm 0.12$ & $0.94 \pm 0.06$ & & \\
\hline Putamen & $1.03 \pm 0.04$ & $1.06 \pm 0.07$ & $1.04 \pm 0.04$ & & \\
\hline Thalamus & $1.00 \pm 0.04$ & $1.02 \pm 0.07$ & $1.01 \pm 0.04$ & & \\
\hline Superior temporal & $1.03 \pm 0.06$ & $1.04 \pm 0.05$ & $1.05 \pm 0.04$ & & \\
\hline Calcarine & $1.16 \pm 0.06$ & $1.10 \pm 0.05$ & $1.17 \pm 0.05$ & $4.8(0.01)$ & $3>2$ \\
\hline Posterior cingulate & $0.89 \pm 0.09$ & $0.86 \pm 0.09$ & $0.92 \pm 0.09$ & & \\
\hline Posterior cingulate - (upper slice) & $1.22 \pm 0.05$ & $1.19 \pm 0.06$ & $1.20 \pm 0.07$ & & \\
\hline Mid temporal & $1.03 \pm 0.02$ & $1.01 \pm 0.03$ & $1.04 \pm 0.04$ & & \\
\hline Parietal-(upper slice) & $0.99 \pm 0.02$ & $0.99 \pm 0.02$ & $0.99 \pm 0.02$ & & \\
\hline Occipital & $1.00 \pm 0.05$ & $0.97 \pm 0.05$ & $0.98 \pm 0.04$ & & \\
\hline Occipital-(upper slice) & $1.01 \pm 0.04$ & $0.98 \pm 0.06$ & $0.99 \pm 0.05$ & & \\
\hline
\end{tabular}

to superior pre-frontal cortex and reduced uptake tocalcarine cortex was found in the diabetic group who had a history of previous severe hypoglycaemia. The effect size of the difference between patient groups and control subjects for each of the regions of interest is illustrated in Figure 2. Although there is no significant excess uptake to superior prefrontal cortex in the patients without hypoglycaemic attacks, a trend in this direction is visible (Fig. 2). The observed differences are small. The isotope uptake was significantly greater in the frontal cortex and significantly reduced in the calcarine cortex in the diabetic patients with a preceding history of severe hypoglycaemia.
Two significant correlations were observed between regional uptake of tracer and duration of diabetes - this number of significant results was not greater than expected by chance (1.5).

\section{Discussion}

This study simultaneously examined the effects of diabetes per se and of recurrent severe hypoglycaemia on the regional cerebral uptake of tracer in IDDM patients. The hypothesis that either diabetes or recurrent severe hypoglycaemia (or both) may cause changes in 
regional cerebral blood flow was prompted by the demonstration of significant neuropsychological impairment in insulin-treated diabetic patients who had been exposed to severe hypoglycaemia $[5,11,12]$. However, not all studies have confirmed that recurrent severe hypoglycaemia results in a permanent intellectual deficit. For example, a 5-year prospective study of the effects of severe hypoglycaemia on cognitive functioning found no detrimental effects of repeated severe hypoglycaemia [26]. This study has been criticised for failing to separate its two study groups adequately in their experience of hypoglycaemia, the use of insensitive and unvalidated cognitive tests, the relatively short time of follow-up, and its insufficient power [27]. A different retrospective study found a correlation between cognitive impairment and the presence of severe polyneuropathy rather than preceding severe hypoglycaemia, although both factors did appear to interact to magnify the degree of neurobehavioural dysfunction [28].

The present study suggests that by comparison with healthy volunteers, in diabetic patients a relative increase in tracer uptake occurs in the superior pre-frontal cortex. This effect was greater in those diabetic patients who had been exposed previously to multiple episodes of severe hypoglycaemia. These patients also had a relative bilateral reduction of tracer uptake in the calcarine cortex. Recurrent hypoglycaemia may have a cumulative effect on altering regional cerebral blood flow in addition to the effects of diabetes per se. The role of other factors as confounding variables potentially influencing the results is worthy of consideration. These include differences in state anxiety or arousal, differences in ambient insulin concentrations and differences in the extent and rate of change from the habitual blood glucose concentration to the target glycaemic levels obtained for scanning. These explanations, while theoretically possible, are unlikely. We were careful to measure anxiety in the two diabetic groups before scanning and there were no betweengroup differences. All three groups were also compared under basal conditions using the Alderley Park State Anxiety Questionnaire [29]. State anxiety was low in all three groups, and there were no differences in anxiety between the control subjects or the two groups of diabetic patients. In addition, anticipatory anxiety has no accepted pattern of effect on regional cerebral perfusion [30] and induced anxiety in phobic patients produced only decreased isotope uptake in posterior association cortex [31]. Further, whether the absence of i.v. dextrose and insulin in the control group could have been a confounding variable for the group difference is doubtful. Diabetic patients are likely to be more familiar with i.v. cannulation procedures than their nondiabetic counterparts. The question of a role for insulin has been addressed by Kerr et al. [32] who demonstrated a symmetry of cerebral blood flow and cognitive response to hypoglycaemia and suggested a late direct effect of insulin per se to increase cerebral blood flow. The direct effect of insulin was seen only after $2 \mathrm{~h}$ in the normoglycaemic hyperinsulinaemic phase, this being much later than the effect we have demonstrated here, which is, therefore, unlikely to be due to insulin. With regard to the influence of the ambient blood glucose concentration and rate of change of this variable, Tallroth et al. [33] have demonstrated that the magnitude of global cerebral blood flow changes from before hypoglycaemia to after recovery were inversely related to the initial blood glucose level, but were unable to identify changes in the relative distribution of regional cerebral blood flow.

The absence of a correlation between regional tracer uptake and the duration of diabetes in our study is consistent with evidence derived from EEG studies in diabetic children [34], in which no correlation was found between the EEG abnormalities and either the duration of diabetes or the quality of metabolic control. This suggested that chronic hyperglycaemia was not the sole causal factor producing permanent EEG abnormalities. By contrast, a history of exposure to severe hypoglycaemia (defined in that study as hypoglycaemia which had required treatment with parenteral glucagon) was strongly associated with the prevalence of EEG abnormalities [34]. A previous study by Grill et al. [35], which used positron emission tomography with ${ }^{18} \mathrm{~F}$-fluoromethane to measure regional cerebral blood flow, demonstrated that under carefully controlled normoglycaemic conditions, global cerebral blood flow was greater in diabetic subjects, and the most marked increments in mean regional cerebral blood flow occurred bilaterally in some areas of the frontal lobes in addition to the primary somato-sensory cortex. The only region in which cerebral blood flow was reduced was the head of the caudate nucleus. In the present study, increments of Exametazime uptake were observed in the frontal cortex. Although a relative excess of Exametazime uptake in the frontal cortex does not provide a direct measure of an increment in blood flow, the previous data of Grill et al. [35] make such an interpretation tenable.

Other studies have also suggested that the frontal cortex is preferentially affected by acute hypoglycaemia. Tallroth et al. [36] studied 10 healthy non-diabetic subjects with SPECT using i.v. ${ }^{133}$ Xenon. Moderate hypoglycaemia (plasma glucose $2.0 \mathrm{mmol} / \mathrm{l}$ ) resulted in a significant increase in regional cerebral blood flow with the highest increments in the frontal and parietal cortices ( 21.5 and $20.6 \%$, respectively).

Further evidence for the localisation of the effects of acute hypoglycaemia on regional cerebral function is provided by a comparative study of EEG and visual evoked potentials during moderate hypoglycaemia [6]. In that study, the EEG was shown to provide a more sensitive neurophysiological response to hypoglycaemia and the earliest EEG changes during hypoglycaemia occurred in the frontal regions of the brain. A predilection for functional impairment of the frontal lobes during acute hypoglycaemia has also been sug- 
gested by the pattern of cognitive dysfunction observed in diabetic and non-diabetic individuals during acute insulin-induced hypoglycaemia $[37,38]$.

The physiological significance of these local changes in cerebral blood flow and metabolism during hypoglycaemia is not known. The similarity in the patterns of regional tracer uptake observed in diabetic patients who had a history of previous severe hypoglycaemia during normoglycaemia, and in non-diabetic and diabetic subjects during acute hypoglycaemia is intriguing, and introduces the possibility that the abnormal pattern of regional brain metabolism observed in diabetic patients who have been exposed to recurrent severe hypoglycaemia is mediated by regionally selective capillary recruitment which has been promoted by preceding episodes of acute hypoglycaemia. It could be speculated that this may represent an adaptive response to maintain a supply of glucose to vulnerable areas of the brain such as the frontal cortex, during subsequent episodes of acute hypoglycaemia. This premise is supported by the finding that in rat brain, bloodbrain glucose transport is increased in response to acute hypoglycaemia $[39,40]$. Glucose transport is also enhanced in a regionally selective manner in response to chronic hypoglycaemia [41]. The mechanisms underlying these changes may be different. The responses to acute hypoglycaemia occur rapidly and have been suggested to be a consequence of capillary recruitment and the primary mobilisation of glucose transporters [42] while the increased synthesis of specific hexose transporters has been proposed as the principal mechanism mediating the response to chronic hypoglycaemia [43]. No studies in diabetic animals have addressed the question of what happens to cerebral glucose transport and metabolism following exposure to recurrent episodes of acute hypoglycaemia, which is a more relevant model for human diabetes.

In summary, the present study has suggested that the pattern of regional cerebral blood flow estimated using SPECT, was altered under basal normoglycaemic conditions in patients with diabetes. These abnormalities were more extensive in diabetic patients who had experienced multiple episodes of severe hypoglycaemia. These observations require replication, and the underlying mechanism of altered cerebral metabolism merits examination using appropriate experimental models.

Acknowledgements. Dr. K. M. MacLeod was funded by the British Diabetic Association and additional support was received from the Wellcome Trust, the Scottish Hospital Endowments Research Trust (Grant 949) and Novo Nordisk Ltd. We also thank Ms. N. Brearley for expert secretarial assistance.

\section{References}

1. Dejgaard A, Gade A, Larsson H, Balle V, Parving A, Parving HH (1991) Evidence for diabetic encephalopathy. Diabetic Med 8: 162-167
2. Reaven GM, Thompson LW, Nahuren D, Haskins E (1990) Relationship between hyperglycemia and cognitive function in older NIDDM patients. Diabetes Care 13: 16-21

3. Richardson JTE (1990) Cognitive function in diabetes mellitus. Neurosci Behav Rev 14: 385-388

4. Ryan CM (1988) Neurobehavioural complications of type I diabetes: examination of possible risk factors. Diabetes Care 11: 86-93

5. Deary IJ (1992) Diabetes, hypoglycaemia and cognitive performance. In: Handbook of human performance. Academic Press, New York, pp 243-260

6. Tamburrano G, Lala A, Locuratolo N et al. (1988) Electroencephalography and visually evoked potentials during moderate hypoglycemia. J Clin Endocrinol Metab 66: 13011306

7. Harrad RA, Cockram CS, Plumb AP, Stone S, Fenwick P, Sönksen PH (1985) The effect of hypoglycaemia on visual function: a clinical and electrophysiological study. Clin Sci 69: 673-679

8. Pramming S, Thorsteinsson B, Stigsby B, Binder C (1988) Glycaemic threshold for changes in electroencephalograms during hypoglycaemia in patients with insulin dependent diabetes. BMJ 296: 665-667

9. Tallroth G, Lindgren M, Stenberg G, Rosen I, Agardh CD (1990) Neurophysiological changes during insulin-induced hypoglycaemia and in the recovery period following glucose infusion in type 1 (insulin-dependent) diabetes mellitus and in normal man. Diabetologia 33: 319-323

10. Bale RN (1973) Brain damage in diabetes mellitus. Br J Psychiatry $122: 337-341$

11. Wredling R, Levander S, Adamson U, Lins PE (1990) Permanent neuropsychological impairment after recurrent episodes of severe hypoglycaemia in man. Diabetologia 33: 152-157

12. Langan SJ, Deary IJ, Hepburn DA, Frier BM (1991) Cumulative cognitive impairment following recurrent severe hypoglycaemia in adult patients with insulin-treated diabetes mellitus. Diabetologia 34: 337-344

13. Deary IJ, Langan SJ, Graham KS, Hepburn DA, Frier BM (1993) Severe hypoglycemia, intelligence and speed of information processing. Intelligence 16:337-359

14. Nelson HE (1982) National adult reading test - Test manual. NFER-Nelson, Windsor, UK

15. Wechsler DA (1981) Wechsler adult intelligence scale - Revised test manual. The Psychological Corporation, New York

16. Spielberger CD, Goduch RL, Lushere RE (1970) Manual for the state-trait anxiety inventory. Consultant Psychologists Press Inc., New York

17. Andersen AR, Friberg H, Lassen NA, Kristensen K, Neirinckx RD (1987) Serial studies of cerebral blood flow using 99m Tc-HMPAO: a comparison with ${ }^{133} \mathrm{Xe}$. Nucl Med Comm 8: 549

18. Yonekura Y, Nishizawa S, Mukai T et al. (1988) SPECT with Tc-HMPAO compared with regional cerebral blood flow measured by PET: effects of linearisation. J Cereb Blood Flow Metab 8: S82-S89

19. Inugami A, Kanno I, Uemura K et al. (1988) Linearisation correction of Tc-labelled HMPAO image in terms of regional CBF distribution: comparison to $\mathrm{C}^{15} \mathrm{O}_{2}$ inhalation steady state method measured by positron emission tomography. $\mathrm{J}$ Cereb Blood Flow Metab 8: S52-S60

20. Gemmell HG, Evans NTS, Besson JAO et al. (1990) Regional cerebral blood flow imaging: a quantitative comparison of Technetium-99m-HMPAO SPECT with $\mathrm{C}^{15} \mathrm{O}_{2}$ PET. J Nucl Med 31: 1595-1600

21. Woods SW, Hegeman IM, Zubal IG et al. (1991) Visual stimulation increases technetium-99m-HMPAO distribution in human visual cortex. J Nucl Med 32: 210-214 
22. Ebmeier KP, Murray CL, Dougall NJ, O'Carroll RE, Goodwin GM (1992) Unilateral voluntary hand movement and regional cerebral uptake of Technetium-99m-Exametazime in human control subjects. J Nucl Med 33: 1623-1627

23. Ebmeier KP, Dougall NJ, Austin M-P et al. (1991) The splitdose technique for the study of psychological and pharmacological activation with the cerebral blood flow marker exametazime and single photon emission computed tomography (SPECT): reproducibility and rater reliability. Int $\mathbf{J}$ Meth Psychiatr Res 1:27-38

24. Gronwall D (1977) Paced auditory serial addition test: a measure of recovery from concussion. Perceptual Motor Skills 44:367-373

25. Talairach J, Zilkha G, Tournoux P, Prosalentis A, BordasFerrier M, Covello L, Iacob M, Mempel E (1988) Atlas d'Anatomie Stereotactique du Telencephale. Masson, Paris

26. Reichard P, Britz A, Rosenquist U (1991) Intensified conventional insulin therapy and neuropsychological impairment. BMJ 303: 1439-1442

27. Deary IJ, Frier BM (1992) Intensified conventional insulin treatment and neuropsychological impairment. BMJ 304: 447

28. Ryan CM, Williams TM, Finegold DN, Orchard TJ (1993) Cognitive dysfunction in adults with type 1 (insulin-dependent) diabetes mellitus of long duration: effects of recurrent hypoglycaemia and other chronic complications. Diabetologia $36: 329-334$

29. Walker LG (1990) The measurement of anxiety. Postgrad Med J 66 [Suppl 2]: S11-S17

30. Drevets WC, Videen TO, MacLeod AK, Haller JW, Raichle ME (1992) PET images of blood changes during anxiety: correction. Science 256: 1696

31. O'Carroll RE, Moffoot APR, Van Beck M et al. (1993) The effect of anxiety induction on the regional uptake of ${ }^{99 \mathrm{~m} T c-}$ Exametazime in simple phobia as shown by single photon emission tomography (SPET). J Affect Dis 28: 203-210

32. Kerr D, Stanley JC, Barron M, Thomas R, Leatherdale BA, Pickard J (1993) Symmetry of cerebral blood flow and cognitive responses to hypoglycaemia in humans. Diabetologia 36: $73-78$
33. Tallroth G, Ryding E, Agardh C-D (1993) The influence of hypoglycaemia on regional cerebral blood flow and cerebral volume in type 1 (insulin-dependent) diabetes mellitus. Diabetologia 36: $530-535$

34. Soltész G, Acsadi G (1989) Association between diabetes, severe hypoglycaemia and electroencephalographic abnormalities. Arch Dis Child 64: 992-996

35. Grill V, Gutniak M, Björkman O et al. (1990) Cerebral blood flow and substrate utilization in insulin-treated diabetic subjects. Am J Physiol 258: E813-E820

36. Tallroth G, Ryding E, Agardh CD (1992) Regional cerebral blood flow in normal man during insulin-induced hypoglycaemia and in the recovery period following glucose infusion. Metabolism 41: 717--721

37. Pramming S, Thorsteinsson B, Theilgaard A, Pinner EM, Binder C (1986) Cognitive function during hypoglycaemia in type I diabetes mellitus. BMJ 292: 647-650

38. Holmes CS, Hayford JT, Gonzalez JL, Weydert JA (1983) A survey of cognitive functioning at different glucose levels in diabetic persons. Diabetes Care 6: 180-185

39. Cremer JS, Cunningham VJ, Seville MP (1983) Relationship between extraction and metabolism of glucose, blood flow and tissue blood volume in regions of rat brain. $\mathbf{J}$ Cereb Blood Flow Metab 3: 291-302

40. Hawkins RA, Mans AM, Davis DW, Hibbard LS, Lu DM (1983) Glucose availability to individual cerebral structures is correlated to glucose metabolism. J Neurochem 40: 10131018

41. Pelligrino DA, Segil LJ, Albrecht RF (1990) Brain glucose utilization and transport and cortical function in chronic vs acute hypoglycemia. Am J Physiol 259: E729-E735

42. Hargreaves RJ, Planas AM, Cremer JE, Cunningham VJ (1986) Studies on the relationship between cerebral glucose transport and phosphorylation using 2-deoxyglucose. J Cereb Blood Flow Metab 6: 708-716

43. McCall AL, Fixman LB, Fleming M, Tornheim K, Chick W, Ruderman NB (1986) Chronic hypoglycemia increases brain glucose transport. Am J Physiol 251: E442-E447 